\title{
Study of the Clinical Profile of Varicose Vein Disease
}

\author{
Raunak Kumar Gupta1, Dilip Kumar Acharya², Sanjay .M .Datey ${ }^{3}$, \\ Kartikeya Shukla ${ }^{4}$, Nikita Chaudhary ${ }^{5}$, Anubhav Jain ${ }^{6}$ \\ ${ }^{1}$ Senior Resident, Department of General Surgery, All India Institute of Medical Sciences, Bhopal, 462020, \\ Madhya Pradesh, India. \\ ${ }^{2,3}$ Professor, Department of General Surgery, Sri Aurobindo Institute of Medical Science, Indore, 453555, \\ Madhya Pradesh, India. \\ ${ }^{4,5,6}$ Resident, Department of General Surgery, Sri Aurobindo Institute of Medical Science, Indore, 453555, \\ Madhya Pradesh, India. \\ Corresponding Author: Dilip Kumar Acharya
}

\begin{abstract}
Introduction: Varicose veins are part of the spectrum of chronic venous diseases and include dilated, tortuous veins of lower limbs, spider telangiectasia and reticular veins. Varicose vein disease is a very common problem of the western world and mostly their patients come for treatment because of cosmetic reasons. Indian scenario is different as mostly patients from lower socioeconomic strata of the society come for complications like ulceration, dermatitis etc. of varicose veins come for treatment. This problem sometimes results in chronic absenteeism from work, economic losses and change of occupation in many individuals.

Methods: This observational study was carried out from $1^{\text {st }}$ January 2017 to $30^{\text {th }}$ June 2018 in Sri Aurobindo Medical College and Postgraduate Institute, Indore. Clinical profile of 52 patients of varicose vein disease was studied. All the patients were thoroughly examined and the pertaining data recorded. This data was tabulated and compared with the available literature on this subject.

Results: Fifty two cases of varicose vein disease were studied. The commonest age group affected with the disease was between 41 to 50 years. Male patients were more and comprised of $84.6 \%$ of total number. Sapheno femoral junction valve was incompetent in $73.1 \%$ cases as compared to saphenopopliteal junction[34.6\%].Obesity was an important factor in causation of varicose vein disease. Flush ligation at SFJ with stripping was the commonest surgical procedure carried out our center.

Conclusion: It is found that varicose vein disease with its associated sequelae brings the patient for treatment in our scenario. Long saphenous vein is the commonly affected part of the superficial venous system because of incompetency of the valve at SFJ. Although various etiological factors can be attributed to varicose vein disease but occupation and obesity remain the main factors. Accurate assessment of problem and adequate surgery will prevent recurrence.
\end{abstract}

Key Words: Varicose veins, venous ulcers, recurrent varicose veins.

\section{INTRODUCTION}

Varicose vein disease is predominantly a cosmetic problem of the females of western world. In our country the overall prevalence is comparatively low and patients commonly present with some complications. Varicose veins have been recognized as a chronic disorder of surgical importance since ancient times. The term "Varicose" was derived from Latin word "VARICOUS", which means "dilated". According to U.S. statistics $23 \%$ of American adults have varicose veins. ${ }^{1}$ If spider telangiectasis and 
reticular veins are also considered, then the prevalence increases upto $80 \%$ in males and $85 \%$ in females ${ }^{2}$

Varicose vein disease is characterized by dilated, elongated and tortuous superficial veins of lower limbs which may permit reverse flow of blood due to faulty valves. In the initial stages of the disease the patient is concerned about the unsightly appearance of dilated tortuous veins, but if left untreated, the later stages are marked by itching due to dermatitis, swelling and ulceration. In the Indian scenario the disease is one of the common surgical problems of low socioeconomic groups. The problem can affect them economically as it can lead to absenteeism from work and sometimes compels them to change the job. This study was carried out with an aim of studying the clinical profile of varicose vein disease. The demographic pattern, clinical presentation, comorbidities, and outcome of the treatment was analysed in the study.

\section{MATERIAL AND METHODS}

This descriptive observational study was carried out from $1^{\text {st }}$ January 2017 to $30^{\text {th }}$ June 2018. In this, the clinical profile of varicose vein disease was studied in 52 patients. The study was initiated after approval of the Institutional Ethics and Research Committee. All admitted patients of varicose vein disease were included in the study as per the inclusion/exclusion criteria. Thorough clinical history recorded and complete clinical examination was carried out with special emphasis on varicose veins and its sequel. All details regarding the management of these patients with specific investigations and operative procedure were recorded on proforma. At the end of the study, the data was entered on a master chart. The collected data was tabulated and Analysis was done by descriptive statistical method. At no stage of this study the individual identity of the patient was disclosed.

\section{OBSERVATIONS AND RESULTS}

Table number 1: distribution of patients according to age and sex

\begin{tabular}{|l|l|l|l|l|l|l|}
\hline \multirow{2}{*}{ Age Group } & \multicolumn{2}{l|}{ Female(8) } & \multicolumn{2}{l|}{ Male(44) } & \multicolumn{2}{l|}{ Total(52) } \\
\cline { 2 - 8 } & No. & \% & No. & \% & No. & \% \\
\hline$<20$ years & 0 & 0.0 & 1 & 2.3 & 1 & 1.9 \\
\hline 21-30 years & 0 & 0.0 & 7 & 15.9 & 7 & 13.5 \\
\hline 31-40 years & 2 & 25.0 & 10 & 22.7 & 12 & 23.1 \\
\hline 41-50 years & 4 & 50.0 & 12 & 27.3 & 16 & 30.8 \\
\hline 51-60 years & 1 & 12.5 & 10. & 22.7 & 11 & 21.2 \\
\hline 61-70 years & 1 & 12.5 & 3 & 6.8 & 4 & 7.7 \\
\hline$>70$ years & 0 & 0.0 & 1 & 2.3 & 1 & 1.9 \\
\hline Total & 8 & 100.0 & 44 & 100.0 & 52 & 100.0 \\
\hline
\end{tabular}

Table No.1 shows the distribution of patients in this study according to age and sex. There were eight females and forty four males in the study, which shows a male preponderance. There was one patient $\{1.9 \%\}$ in age group between $21-30$ years. Twelve patients were in the age group 3140 years. Maximum patients $\{30.8 \%\}$ were from the age group between $41-50$ years followed by the age group between 31 to 40 years This denotes that most of the patients $\{<50 \%\}$ of varicose vein disease seek surgical treatment in their middle age. This can be attributed to the complications like pain, discoloration and ulceration, which start after prolonged conservative measures. This can be an important socioeconomical fact, as individuals from this age group are the sole bread winners of their families. Any absenteeism from work because of disease or complication of the treatment can be disastrous to their family.

Table number 2: distribution of patients according to occupation

\begin{tabular}{|l|l|l|}
\hline Occupation & No. & \% \\
\hline Farmer & 20 & 38.5 \\
\hline Construction worker & 8 & 15.4 \\
\hline Laborer & 6 & 11.5 \\
\hline Coolie & 5 & 9.6 \\
\hline Housewife & 5 & 9.6 \\
\hline Shopkeeper & 2 & 3.8 \\
\hline Student & 2 & 3.8 \\
\hline Bus conductor & 1 & 1.9 \\
\hline Daily wage worker & 1 & 1.9 \\
\hline Machine turner & 1 & 1.9 \\
\hline Police trainee & 1 & 1.9 \\
\hline Total & 52 & 100.0 \\
\hline
\end{tabular}

The above table No 2 shows the distribution of patients in this study according to their Occupation. There were $20\{38.5 \%\}$ farmers, $8\{15.4 \%\}$ construction workers, 6 labourers, $5\{9.6 \%\}$ were coolies. Remaining twenty percent patients 
were doing sedentary jobs like being housewife, students and office work. This clearly indicates that individuals involved in hard physical work are more prone to get varicose vein disease and its complications.

Table number 3: distribution of patients according to limb involvement

\begin{tabular}{|l|l|l|}
\hline Lower limb involvement & No. & \% \\
\hline Bilateral & 23 & 44.2 \\
\hline Unilateral & 29 & 55.8 \\
\hline Total & 52 & 100.0 \\
\hline
\end{tabular}

The above table shows the distribution of patients according to lower limb involvement. There were $29\{55.8 \%\}$ patients with unilateral lower limb involvement, whereas $23\{44.2 \%\}$ had bilateral lower limb involvement.

Table number 4: distribution of patients according to presenting complaints

\begin{tabular}{|l|l|l|}
\hline Presenting Complains & No. & \% \\
\hline Dilated veins & 47 & 90.4 \\
\hline Skin changes & 36 & 69.2 \\
\hline Dull aching night pain & 26 & 50.0 \\
\hline Ulcer & 21 & 40.4 \\
\hline Edema & 17 & 32.7 \\
\hline
\end{tabular}

The above table $\{$ Table No.4 \} shows the complaints with which the patients presented. Forty seven $\{90.4 \%\}$ presented with dilated veins, while $37 \quad\{69.2 \%\}$ presented with skin changes. Dull aching night pain was a complaint in 26 patients. Twenty one $\{40.4 \%\}$ presented with ulceration. Majority of patients presented with dilated veins and skin changes.

Table number 5: patients with comorbidities

\begin{tabular}{|l|l|l|}
\hline Associated Comorbidities & No. & \% \\
\hline Hypertension & 11 & 21.2 \\
\hline Diabetes Mellitus type-2 & 12 & 23.1 \\
\hline
\end{tabular}

Table number 5 shows the distribution of patients according to the comorbidities. Hypertension $\{21.2 \%\}$ and Diabetes Mellitus $\{23.1 \%\}$ were the comorbidities seen in the 52 patients of this study.

Table number 6: patients with previous limb surgery

\begin{tabular}{|l|l|l|}
\hline Previous leg surgery & No. & \% \\
\hline Ligation of dilated veins left lower limb & 1 & 33.3 \\
\hline Stripping of varicose veins ligation at SFJ & 2 & 66.7 \\
\hline Total & 3 & \\
\hline
\end{tabular}

The above table shows patients with previous surgery for the same problem. These are the three patients of recurrent varicose vein disease. One patient had undergone Ligation of perforators and the other two had Ligation at saphenofemoral junction with stripping of the vein.

Table number 7: patients with previous deep vein thrombosis

\begin{tabular}{|l|l|l|}
\hline Previous DVT & No. & \% \\
\hline No & 49 & 94.2 \\
\hline Yes & 3 & 5.8 \\
\hline Total & 52 & 100.0 \\
\hline
\end{tabular}

The above table shows the number of patients with a history of deep vein thrombosis in the affected limb in the past. There was a history of deep vein thrombosis in $3\{5.8 \%\}$ out of 52 patients in the study.

Table number 8: distribution of patients according to BMI

\begin{tabular}{|l|l|l|}
\hline BMI (WHO Classification) & No. of patients & \% \\
\hline Normal Weight $\left(18.5-24.9 \mathrm{~kg} / \mathrm{m}^{2}\right)$ & 32 & 61.5 \\
\hline Overweight $\left(25.0-29.9 \mathrm{~kg} / \mathrm{m}^{2}\right)$ & 17 & 32.7 \\
\hline Obese $\left(>30 \mathrm{~kg} / \mathrm{m}^{2}\right)$ & 3 & 5.8 \\
\hline Total & 52 & \\
\hline
\end{tabular}

The above table shows the distribution of patients according to BMI. The BMI was classified according to WHO classification. There were $32\{61.5 \%\}$ patients in the group of normal weight. Seventeen $\{32.7 \%\}$ out the 52 in the study overweight and $3\{5.8 \%\}$ were in the obese group.

Table number 9: distribution of patients according to doppler findings

\begin{tabular}{|l|l|l|}
\hline Doppler Findings & No. of patients & $\mathbf{\%}$ \\
\hline SFJ incompetence & 38 & 73.1 \\
\hline SPJ incompetence & 18 & 34.6 \\
\hline Perforator incompetence & 47 & 90.4 \\
\hline Dilated tortuous GSV / SSV & 42 & 80.8 \\
\hline DVT & 3 & 5.8 \\
\hline
\end{tabular}

The above table shows the distribution of patients according to Doppler findings. There were $38\{73.1 \%\}$ patients with SFJ incompetence and $18\{34.6 \%\}$ with SPJ incompetence. Forty seven $\{90.4 \%\}$ had in competence of valves of perforator veins. Three patients had deep vein thrombosis which resulted in secondary varicose veins.

Table number 10: distribution of patients according to surgeries performed

\begin{tabular}{|l|l|l|}
\hline Surgery & Frequency & Percent \\
\hline SFJ flush ligation with stripping of LSV & 2 & 6.1 \\
\hline $\begin{array}{l}\text { SFJ flush ligation with stripping of LSV with } \\
\text { perforator ligation }\end{array}$ & 16 & 48.5 \\
\hline $\begin{array}{l}\text { SFJ, SPJ flush ligation with stripping of LSV } \\
\text { with incompetent perforator ligation }\end{array}$ & 9 & 27.3 \\
\hline $\begin{array}{l}\text { SPJ ligation with stripping of SSV with } \\
\text { incompetent perforator ligation }\end{array}$ & 1 & 3.0 \\
\hline $\begin{array}{l}\text { SPJ ligation with incompetent perforator } \\
\text { ligation }\end{array}$ & 2 & 6.1 \\
\hline Perforator ligation & 3 & 9.1 \\
\hline Total & 33 & \\
\hline
\end{tabular}


The above table shows various types of surgical treatment the patients of this study. Out of the thirty three operated patients $27\{82 \%\}$ had undergone ligation at saphenofemoral junction and stripping of the long saphenous vein. In three $\{9 \%\}$ patients the sapheno popliteal junction was ligated and remaining three only the perforators were ligated.

\section{DISCUSSION}

The observational study on the clinical profile of Varicose Vein Disease was conducted in the Department of Surgery of Sri Aurobindo Medical College and Postgraduate Institute from January 2017 to June 2018. This study was planned with the aim to identify the various demographical, clinicopathological and occupation related factors in the causation of varicose vein disease in the population served by our center. Two-third of the patients in our study were from the age group between 21 to 50 years. If the patients between 51 to 60 years are added then it becomes almost 90\%.In a study done by Mulla et al, mean age of the study population was 45.6 years with a range of 21 to 70 years. ${ }^{3}$ Gad et al. found $90 \%$ of patients in the age group between 20 to 56 years. ${ }^{4}$ This age group is the backbone of any society. They are the breadwinner of family and any disease in this age group can affect the welfare of family. Morbidity due to varicose veins disease can lead to absenteeism from work and financial losses. Associated morbidities such as diabetes and hypertension can further aggravate the problem. Diabetes Mellitus can be a detrimental actor in the outcome from surgical treatment of varicose vein disease. As the age advances, comorbidities start playing an important role in the outcome of surgery. In our study, out of 52 patients 44 were males, which shows a clear male preponderance. This could be explained by the fact that the males were involved in such occupations which needed prolonged standing. Our study had twenty farmers and twenty one construction workers. In a study on the incidence of varicose veins in factory workers by Widmer et al., it was found that among the male and female factory workers, the incidence was higher in males. ${ }^{5}$.Secondly we believe that the female population in our society does not come with complaints of varicose veins of lower limb because the lower limbs are well covered in all ethnic dresses. Whereas the male population become aware of the varicose veins because of persistent pain in calves due to engorged veins, dermatitis, and varicose ulcers. In the western world the male and female ratio of varicose veins is equal. Abramson et al. conducted a study in Jerusalem which showed four times higher incidence of varicose veins in females. They attributed the higher incidence to obesity in these females as the major contributory factor in the causation of varicose veins. ${ }^{6}$ Our study had $29\{55.8 \%\}$ patients with unilateral varicose veins, whereas $23\{44.2 \%$ patients had bilateral involvement. Mishra et al. in a study of 60 patients, found $54\{90 \%\}$ patients with unilateral involvement, which is a similar finding to our study. Presentation with involvement of unilateral limb does not rule out the possibility of of disease in other limb at a later date. ${ }^{7}$ In our study the commonest symptom was pain which was seen in 47 out of 52 patients,. Thirty six $\{69 \%\}$ patients presented with skin changes and $26\{50 \%\}$ came for treatment of varicose veins with varicose ulcer. W.B. Campbell et al. in their study reported that $50 \%$ patients came for cosmetic reasons for the treatment of varicose veins. Varicose veins lead to disfigured lower limb due to unsightly tortuous dilated veins and stasis dermatitis with pigmentation. In our country pain is the most common presenting feature as shown in various studies. ${ }^{8}$ Obesity has a definite role in the causation of varicose vein disease. In our study 20 patients $\{38 \%\}$ had BMI higher than $25 \mathrm{Kg} / \mathrm{m} 2$. In the study done by Mishra et al. half of their patients were overweight or obese, Increase in BMI is an important determining factor in the etiology of varicose vein disease. Davies et 
al. have coined a term "Phlebesity", in the description of varicose veins in obese in their review article. Clinical and pathophysiological correlation of obesity and varicose veins, chronic insufficiency is well established. Clinical severity of venous insufficiency worsens in obese patients. ${ }^{9}$ Out of the 52 patients thirty three were operated and followed. Although the follow up was short, as the study period extended for 18 months .A long term follow up is necessary to assess the results of surgery. The most common surgery performed was Trendelenburg ligation at saphenofemoral junction with stripping of long saphenous vein and ligation of perforators. Gad et al. have studied the problem of recurrence after surgery and conclude that SFJ ligation with stripping has the lowest recurrence. ${ }^{4}$ Reason for recurrence could be progression of disease, anatomical anomaly overlooked at the initial surgery or neovascularization. ${ }^{10} \mathrm{In}$ our study average stay of patients was seven days, with a range between 6-10 days. Huded et al. reported that $40 \%$ of their patients stayed for 6-10 days. ${ }^{11}$. Both studies have similar figures. Our study was conducted for a short period, hence the number was less and follow up was not adequate. We recommend long term studies to have better perspective of the varicose vein disease in our country. The problem of varicose vein is important as the patients can have prolonged morbidity and absenteeism from work. Newer advancement in the treatment of varicose veins, especially endovascular laser ablation, radiofrequency ablation therapies have shown promising results however expensive and presently, out of reach of all the patients.

Acknowledgement: None

Conflict of Interest: None

Source of Funding: None

\section{Ethical Approval: Approved}

\section{REFERENCES}

1. Hamdan A. Management of varicose veins and venous insufficiency. JAMA.2012; 308: 2612-2621

2. Bergan JJ,Schmid-Schonbein GW, Smith PD, Nicolaides AN, Boisseau MR, Eklof B. Chronic venous disease. N Engl J Med. 2006;355:488-498

3. Mulla SA, Pai S. Varicose veins: A clinical study. Int Surg J 2017 Feb;4[2]:529-533

4. Gad MA,Saber A,Hokkam EN. Assessment of causes and patters of recurrent varicose veins after surgery. N Am J Med Sci. 2012 Jan;4[1]:45-48

5. Widmer L. Prevalence and socioeconomical impotyance-observations in 4529 apparently healthy persons from Basle III study.In peripheral venous disorders,Huber:Bern Haus, 1978

6. Abramson JH, Hopp C, Epstein LM.The epidemiology of varicose veins.A survey in western Jerusalem. J Epidimiol Community Health.1981 Sep;35[3]:213-217

7. Mishra S, Ali I, Singh G. A study of epidemiological factors and clinical profile of primary varicose veins. Med J DY Patil University 2016;[9:61] 617-621

8. Campbell WB. Venous ulceration . J Dermatol Surg Onco 2003;19:764-768

9. Davies HO,Popplewell M, Singhal R, Smith $\mathrm{N}$, Bradbury AW. Obesity and lower limb venous disease. The epidemic of phlebisity. Phlebology 2017 May ;32[4]:227-233

10. Allaf FN, Welch M. Recurrent Varicose Veins. Inadequate surgery remains a problem. Phlebology 2005; 20:138-140.

11. Huded V, Dash S, Das SK, Das S, Sahu R, Choudhary $\mathrm{S}$ et al. Clinical case study of varicose veins. Journal of Evidence Based Medicine and Healthcare 2014;1[7]: 802816

How to cite this article: Gupta RK, Acharya DK, Datey SM et.al. Study of the clinical profile of varicose vein disease. Int J Health Sci Res. 2021; 11(8): 6-10. DOI: https://doi.org/10. 52403/ijhsr.20210802 